Iwona Zarzyka

\title{
PROPERTIES OF POLYURETHANE FOAMS WITH OXAMIDE AND BORATE GROUPS
}

\author{
Department of Organic Chemistry, Faculty of Chemistry, Rzeszow University of Technology, \\ 6, Al. Powstancow Warszawy, 35-959 Rzeszow, Poland; izarzyka@ prz.edu.pl
}

Received: N ovember 05, 2012 / Revised: J anuary 22, 2013 / Accepted: M arch 23, 2013

() Zarzyka I., 2013

\begin{abstract}
The conditions of polyurethane foams preparation with the use of new boroorganic compounds as polyols have been presented. The new polyols have been obtained by two methods: in reactions of N,N'-bis(2hydroxyethyl)oxamide (BHEOD) and boric acid (BA) with excess of ethylene carbonate (EC) and in reactions of BHEOD esterified with BA with excess of EC. The results of determination of foaming process parameters as well as of investigation of the foams properties have been given.
\end{abstract}

Keywords: rigid polyurethane foams, oxamide, boric acid, hydroxyalkylation, modification of structure, thermal stability, compressive strength.

\section{Introduction}

In the seventies of the twentieth century oxamide (OD) was used in many branches of industry [1-3]. Its derivative N,N'-bis(2-hydroxyethyl)oxamide (BHEOD) has also found application in industry, the synthesis of polymers including BHEOD was used for manufacturing of the flame-retardant polyurethanes [4], amido-urethanes [5], and tension-resistant flexible fibers [6]. BHEOD was also used as a component in the flame-retardant polyurethane foams. The presence of BHEOAD not only decreased flammability but at the same time did not deteriorate any mechanical properties of the foamed polyurethane plastics [7].

Nowadays literature data indicate that boric acid and organic boron compounds are used in the production of polymeric materials increasingly. Their role is to reduce flammability and to improve some of physical and mainly mechanical properties of plastics such as enhancing compressive strength and reducing brittleness [8-10].

In this work hydroxyethyl derivatives of OD and boric acid (BA) as a mixture or bonded chemically was used in order to obtain foamed polyurethane materials. It was expected that polyurethane foams should be characterized by high thermal stability due to the presence of oxamide group and good compressive strength due to boron and oxamide groups presence.

Boron was introduced into the structure of polyurethane foams via the modification of polyol component by boric acid. The modification of polyol was made according to two ways. In the first method a homogenous mixture of BHEOD and BA was hydroxyalkylated with excess of ethylene carbonate (EC), so the polyol was a mixture of hydroxyethyl derivatives of OD and BA. In the second method borate groups were incorporated into the structure of hydroxyethyl derivatives of OD.

With the participation of the mentioned polyol components the rigid foamed polyurethane plastics have been obtained, and then their properties have been determined and compared.

\section{Experimental}

\subsection{Syntheses}

\subsubsection{Homogenization of BHEOD and BA}

In a round bottom flask $44 \mathrm{~g}(0.25 \mathrm{~mol})$ BHEOD (obtained according to [11]) and $31 \mathrm{~g}(0.50 \mathrm{~mol}) \mathrm{BA}$ (pure, $\mathrm{POCH}$, Poland) were placed. The reaction mixture was stirred mechanically at temperature $423 \mathrm{~K}$ to until getting a homogenous mixture (5 min).

\subsubsection{Reactions of the mixture of BHEOD and BA with excess of EC}

In a $250 \mathrm{~cm}^{3}$ three-necked round bottom flask $75 \mathrm{~g}$ mixture consisting of $44 \mathrm{~g}(0.25 \mathrm{~mol})$ BHEOD and $31 \mathrm{~g}$ $(0.50 \mathrm{~mol}) \mathrm{BA}$ and the appropriate amount of EC (pure, Fluka, Switzerland) were placed to reach the molar ratio of reagents of $1: 10$ or $1: 14$ and 3.1 or $4.1 \mathrm{~g}$ potassium carbonate (pure for analysis, $\mathrm{POCH}$, Poland) (12.42 or 
$16.56 \mathrm{~g} / \mathrm{mol}$ BHEOD, 0.09 or $0.12 \mathrm{~mol} / \mathrm{mol} \mathrm{BHEOD)} \mathrm{was}$ added. The reaction mixture was protected from moisture and stirred mechanically at $433 \mathrm{~K}$ with monitoring of reaction progress by determination of unreacted EC [12].

\subsubsection{Reactions of BHEOD with EC}

In a $250 \mathrm{~cm}^{3}$ three-necked round bottom flask $44 \mathrm{~g}$ (0.25 mol) BHEOD and $88 \mathrm{~g} \mathrm{(1} \mathrm{mol)} \mathrm{EC} \mathrm{(pure,} \mathrm{Fluka,}$ Switzerland) were placed (molar ratio of reagents 1:4) and $3.1 \mathrm{~g}$ potassium carbonate $(12.42 \mathrm{~g} / \mathrm{mol}$ BHEOD, 0.09 $\mathrm{mol} / \mathrm{mol}$ BHEOD) was added. The reaction mixture was stirred mechanically at $433 \mathrm{~K}$ with monitoring of reaction progress by determination of unreacted EC.

\subsubsection{Reactions of $\mathbf{N}, \mathbf{N}, \mathbf{N}$ ',N'- tetrakis(hydroxyethyl) derivatives of $O D$ (THEOD) with BA}

In a round bottom flask $88 \mathrm{~g}(0.25 \mathrm{~mol})$ THEOD (obtained according to 2.1.3) and $31 \mathrm{~g}(0.50 \mathrm{~mol}) \mathrm{BA}$ were placed. The reaction mixture was stirred mechanically at $393 \mathrm{~K}$. The progress of reaction was monitored by determination of acid number and weight loss of reaction mixture.

\subsubsection{Reactions of THEOD diborate with an excess of EC}

In a $250 \mathrm{~cm}^{3}$ three-necked round bottom flask 70.4 $\mathrm{g}(0.2 \mathrm{~mol})$ THEOD esterified with BA (EBOD) and the appropriate amount of EC (pure, Fluka, Switzerland) were placed to reach the molar ratio of reagents $1: 6$ or $1: 10$ and 2.5 or $3.3 \mathrm{~g}$ potassium carbonate $(12.42$ or $16.56 \mathrm{~g} / \mathrm{mol}$ THEOD, 0.09 or $0.12 \mathrm{~mol} / \mathrm{mol}$ THEOD) was added. The reaction mixture was stirred mechanically at $433 \mathrm{~K}$ with monitoring of progress of reaction by determination of unreacted EC.

\subsubsection{Foams preparation}

Attempts of foaming the new obtaining polyols were carried out in small $250 \mathrm{~cm}^{3}$ test cups at room tem- perature. To $10 \mathrm{~g}$ of hydroxyethyl derivatives of OD, $0.1 \mathrm{~g}$ of surfactant (Silicon L6900, Momentive, US), 1.9-7.5 wt \% of triethylamine (TEA) catalyst (pure, Avocado, Germany), and $6 \mathrm{wt} \%$ of water were added. After careful mixing of the components, a pre-weighed amount of 4,4'-diphenylmethane diisocyanate (pure, Merck, Germany) was added. Each composition was vigorously mixed until it started to cream (see Table 2). The samples for testing were cut out from the foams thus obtained after ca. $48 \mathrm{~h}$.

\subsection{Analytical Methods}

The following properties of foams were determined: apparent density [13], glass transition temperature (by DSC) and the compressive strength [14], thermal stability by DTG and TG analyses and as the weight loss after heating at 423,448 and $473 \mathrm{~K}$ for a month (to reach constant weight).

The differential scanning calorimetry (DSC) measurements of foams were made using a DSC822e Mettler Toledo instrument, in the temperature range of 293-473 K and $10 \mathrm{deg} / \mathrm{min}$ heating rate under nitrogen atmosphere. The results were recorded as heat flow in $(\mathrm{W} / \mathrm{g})$ vs temperature.

Thermal analyses (DTG and TG) of polyurethane foams were performed in ceramic crucible, in the temperature range of $273-873 \mathrm{~K}$, on app. $2 \mathrm{mg}$ sample, under a nitrogen atmosphere with Termowaga TGA/DSC 1 derivatograph, Mettler.

\section{Results and Discussion}

Polyols with oxamide groups modified with BA were obtained in the reactions of BHEOD and BA with an excess of EC in two methods (Table 1).

In the first method homogeneous mixture of BHEOD (I) and BA was reacted with excess of EC (Table 1, synth. 1 and 2):<smiles></smiles>

where: $\mathrm{m}+\mathrm{t}+\mathrm{y}+\mathrm{k} \leq 12$ or $16, \mathrm{~s}+\mathrm{z}+\mathrm{t} \leq 10$ or 14 
In the second method BHEOD was reacted with 4-molar excess of EC and then this derivative (IV, THEOD) was esterified with BA. Borate (V, EBOD) was reacted with excess of EC (Table 1, synth. 3 and 4):

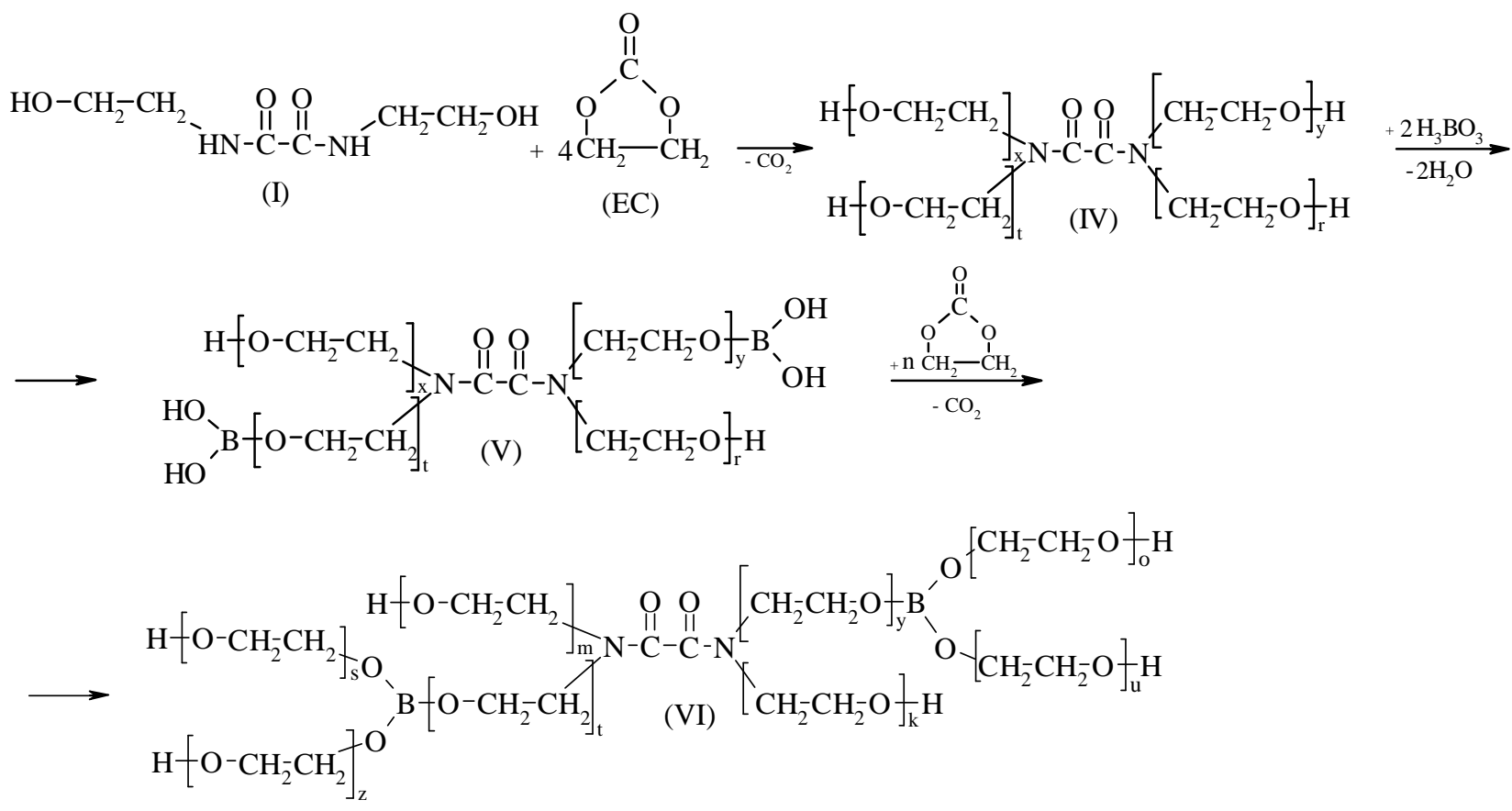

where: $\mathrm{m}+\mathrm{t}+\mathrm{y}+\mathrm{k}+\mathrm{s}+\mathrm{z}+\mathrm{u}+\mathrm{o} \leq 12$ or 16

Table 1

Conditions of polyols obtaining

\begin{tabular}{|c|c|c|c|c|c|}
\hline Synth. & $\begin{array}{c}\text { Initial molar ratio } \\
\text { BHEOD:EC:BA:EC }\end{array}$ & $\begin{array}{c}\text { Amount of } \mathrm{K}_{2} \mathrm{CO}_{3}, \\
\text { mol/mol BHEOD }\end{array}$ & $\begin{array}{c}T, \\
\mathrm{~K}\end{array}$ & $\begin{array}{c}\text { Reaction } \\
\text { time, } \mathrm{h}\end{array}$ & $\begin{array}{c}\text { Molar ratio BHEOD:x } \\
\text { in post-reaction mixture }\end{array}$ \\
\hline 1 & $1: 0: 2: 10$ & 0.09 & 433 & 24 & $1: 9.50$ \\
\hline 2 & $1: 0: 2: 14$ & 0.12 & 433 & 20 & $1: 13.32$ \\
\hline 3 & $1: 4: 2: 6$ & 0.09 & 433 & $3+1.5+12$ & $1: 9.48$ \\
\hline 4 & $1: 4: 2: 10$ & 0.12 & 433 & $3+1.5+10$ & $1: 13.31$ \\
\hline
\end{tabular}

Note: $\mathrm{x}$ - oxyethylene unite.

Table 2

Parameters of foaming process

\begin{tabular}{|c|c|c|c|c|c|c|c|}
\hline \multirow{3}{*}{$\begin{array}{c}\text { Molar ratio } \\
\text { BHEOD:EC:BA:EC in polyol }\end{array}$} & \multirow{3}{*}{ Comp. } & \multicolumn{3}{|c|}{ Composition, g/100 g polyol } & \multirow{2}{*}{\multicolumn{3}{|c|}{$\begin{array}{l}\text { Course of foaming } \\
\text { time, } s\end{array}$}} \\
\hline & & \multirow{2}{*}{ isocyanate $^{*}$} & \multirow{2}{*}{ water } & \multirow{2}{*}{ catalyst $^{* *}$} & & & \\
\hline & & & & & creaming $^{\mathrm{a}}$ & expanding $^{\mathrm{b}}$ & drying $^{c}$ \\
\hline $1: 0: 2: 10$ & F1(10) & 208 & 6 & 1.87 & 54 & 82 & 40 \\
\hline $1: 0: 2: 14$ & F1(14) & 248 & 6 & 7.48 & 43 & 15 & 20 \\
\hline 1:4:2:6 & F2(10) & 268 & 6 & 6.23 & 38 & 36 & 1 \\
\hline $1: 4: 2: 10$ & F2(14) & 248 & 6 & 3.46 & 22 & 16 & 1 \\
\hline
\end{tabular}

Notes: * 4,4'-diphenylmethane diisocyanate; $* *$ triethylamine; ${ }^{a}$ creaming time: the time elapsed from the moment of mixing to the start of volume expansion; ${ }^{b}$ expanding time: the time from the start of expansion to the moment of reaching the sample final volume; ${ }^{c}$ drying time: the time from reaching by the sample its final volume to the moment of losing its surface adhesion to powdered substances. 
In both methods the same initial molar excess of EC was used thus the oxyethylene units excess in relation to OD was identical (1:12 and 1:16). Furthermore in both methods 2-molar excess of BA in relation to OD was applied.

New polyols obtained (mixture II and III as well as VI) were used for polyurethane foams preparation. Parameters of foaming process and foams compositions were given in Table 2 .

It has been stated that apparent density of all foams was within the range of $33-60 \mathrm{~kg} / \mathrm{m}^{3}$ (Fig. 1). The foams prepared with the participation of polyols obtained at larger excess of EC (that means with lower boron content) were characterized by lower apparent density $\left(33-40 \mathrm{~kg} / \mathrm{m}^{3}\right)$, whereas density of foams with higher boron content was of $58-60 \mathrm{~kg} / \mathrm{m}^{3}$.

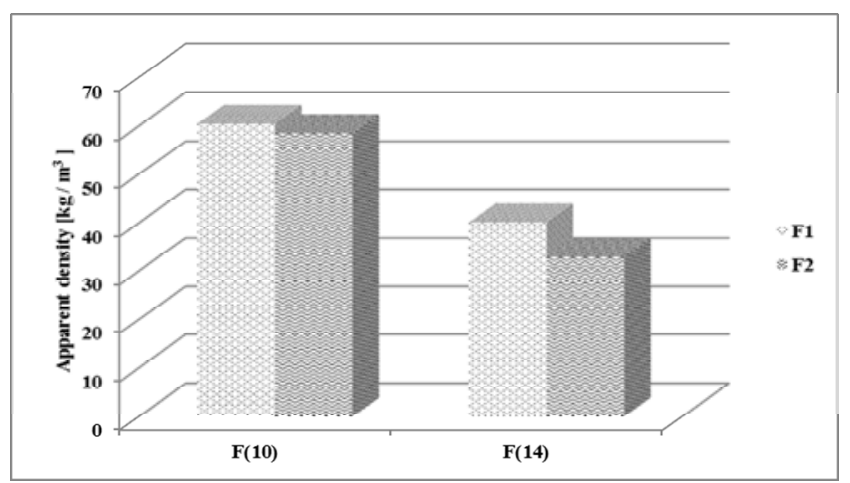

Fig. 1. Apparent density of obtained polyurethane foams

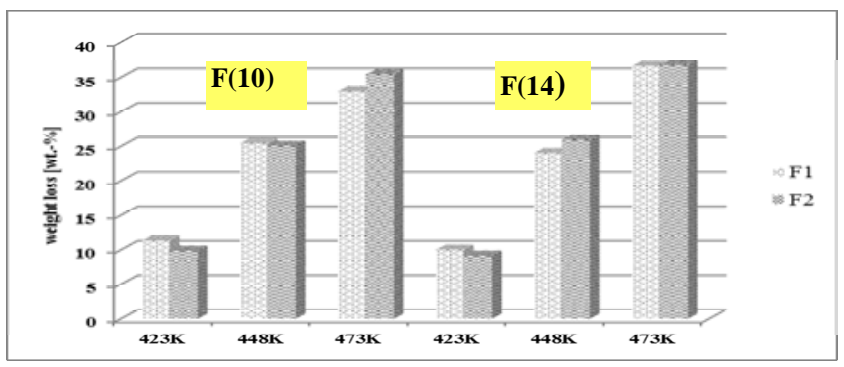

Fig. 2. Thermal stability of foams measured by weight loss fter annealing for 30 days

The glass transition temperature of all foams was in the range of 370-390 K (Table 3). However, the glass transition temperature of the obtained foams was higher than room temperature; these foams were classified as rigid ones [15].

Thermogravimetric analysis demonstrated high thermal stability of the obtained polyurethane foams (Table 3). 5\% weight loss occurs only at about 483 to $493 \mathrm{~K}$ and the temperature of maximum decomposition was in the range of 538-693 K (Table 3). To essential influence of polyol type on thermal stability of the obtained foams has been stated.
Table 3

Thermal stability and glass transition temperature of the polyurethane foams

\begin{tabular}{|c|c|c|c|c|c|c|}
\hline Comp. & $\begin{array}{c}T_{5 \%}, \\
\mathrm{~K}\end{array}$ & $\begin{array}{c}T_{10 \%}, \\
\mathrm{~K}\end{array}$ & $\begin{array}{c}T_{20 \%}, \\
\mathrm{~K}\end{array}$ & $\begin{array}{c}T_{50 \%}, \\
\mathrm{~K}\end{array}$ & $T_{\max }, \mathrm{K}$ & $T g, \mathrm{~K}$ \\
\hline F1(10) & 493 & 513 & 533 & 598 & $\begin{array}{c}538,583 \text { and } \\
673\end{array}$ & 380.5 \\
\hline F1(14) & 483 & 513 & 533 & 578 & 568 & 370.3 \\
\hline F2(10) & 483 & 503 & 528 & 578 & 563 and 678 & 370.0 \\
\hline F2(14) & 488 & 508 & 518 & 573 & 553 and 693 & 390.1 \\
\hline
\end{tabular}

Note: $T_{x \%}$-temperature at which the weight loss is $x \%$.

In order to investigate the possibility of work of the foams at the temperature $423 \mathrm{~K}$ and higher the weight loss was measured during the foams heating for 30 days at 423, 448 and $473 \mathrm{~K}$ (Fig. 2). The foams heated at $423 \mathrm{~K}$ showed the lowest value of weight loss (9.2-11.3 wt \%). Weight losses were comparable for the foams obtained from both types of polyols, but in case of foams from polyols synthesized by the first method weight losses were slightly lower (lower than 10 wt \%, Fig. 2).

The foams were also subjected to strength tests by investigating compressive strength before temperature exposition and after heating at $423 \mathrm{~K}$. The direction of foams compression was in line with the direction of foams growth. The foams were characterized by the compressive strength within the range of $0.17-0.27 \mathrm{MPa}$ (Table 4). The foams obtained with participation of the polyols synthesized in the second method were characterized by a bit higher compressive strength (Table 4).

Table 4

Compressive strength of polyurethane foams

\begin{tabular}{|c|c|c|}
\hline \multirow{2}{*}{ Comp. } & \multicolumn{2}{|c|}{ Compressive strength* $(\sigma M), \mathrm{MPa}$} \\
\cline { 2 - 3 } & without heating & after exposition at 423 K \\
\hline F1(10) & $0.25 \pm 0.02$ & $0.28 \pm 0.02$ \\
\hline F1(14) & $0.17 \pm 0.01$ & $0.24 \pm 0.01$ \\
\hline F2(10) & $0.27 \pm 0.02$ & $0.27 \pm 0.02$ \\
\hline F2(14) & $0.22 \pm 0.02$ & $0.24 \pm 0.01$ \\
\hline
\end{tabular}

Note: *measured by $10 \%$ deformation.

The compressive strength of foams with higher boron content was higher (Table 4, comp. F1(10) and F2(10)) than in foams with lower boron content, as the result of their higher apparent density. The compressive strength of foams increased after their heating at $423 \mathrm{~K}$ and larger changes was observed in case of foams obtained from polyols synthesized by the first method (Table 4, comp. F1(10) and F1(14)).

The properties of the obtained polyurethane foams were compared with the properties of other rigid polyurethane foams, i.e. properties of foams prepared with participation of Rokopl RF-55 [9, 10]. The density of the 
reference foams is about $36.9 \mathrm{~kg} / \mathrm{m}^{3}$ and is comparable with the density of foams obtained from both polyols containing lower boron content $\left(33-40 \mathrm{~kg} / \mathrm{m}^{3}\right.$, Fig. 1, F1(14) and F2(14)).

It was noticed that the compressive strength of reference foams was $0.24 \mathrm{MPa}$ whereas compressive strength of foams modified with boron was comparable or slightly lower $(0.22$ and $0.17 \mathrm{MPa})$. In turn, reference foams had lower thermal stability; their $5 \%$ weight loss occurred at $458 \mathrm{~K}$, while that for the foams modified with boron - at $483 \mathrm{~K}$. Furthermore, the temperature of the maximum decomposition of these foams was higher than $553 \mathrm{~K}$ and that of the reference foams was $483 \mathrm{~K}$.

\section{Conclusions}

Most of the properties, i.e. apparent density and thermal stability, of polyurethane foams with oxamide and borate groups obtained from polyols synthesized by two different methods are similar.

The foams exhibit some differences in thermal resistance and compressive strength. The foams obtained from polyols synthesized by the second method show slightly lower weight loss after annealing to constant weight at the temperature of $423 \mathrm{~K}$ and slightly higher compressive strength.

Polyurethane foams obtained from both types of polyols are characterized by higher thermal stability while slightly lower compressive strength as compared with the reference foams.

\section{References}

[1] Lorenzoni L., Messina G. and Bruzzi V.: Eur. Pat. 271 161, Publ. July 15, 1988; CA: 109, 189854q, Publ. Nov. 21, 1988.
[2] Kawashima Y. and Yamanouchi A.: Jap.Pat. 7406 678. Publ. Nov. 20, 1974; CA: 81, 170783x, Publ. Oct. 30, 1974.

[3] Beck H.: US Pat. 3896 100, Publ. July 22, 1975; CA: 83, 180250b, Publ. Dec. 01, 1975.

[4] Reetz T. and Britain J.: US pat. 3719 639, Publ. Mar. 06, 1973; CA:79, 6515z, Publ. June 16, 1973.

[5] Bassilios H., Farag A., Asfour H: Kolor. Ert., 1974, 16, 19.

[6] Sakata K., Tanabe T., Yamashiro S. et al.: Jap.Pat. 20 299, Publ. Oct. 03, 1964; CA: 68, 22685h, Publ. Feb. 05, 1968.

[7] Haas P., Hettel H. and Ruckes A.: Pat. DE 3 829 958, Publ. Mar. 08, 1990; CA: 113, 41996z, Publ. Aug. 06, 1990.

[8] Czuprynski B., Liszkowska J. and Paciorek-Sadowska J.: Polimery, 2004, 49, 179.

[9] Paciorek-Sadowska J., Czupryski B., Liszkowska J. and Jaskolowski W.: Polimery, 2010, 55, 99.

[10] Paciorek-Sadowska J.: ibid, 373.

[11] Strain F.: Pat. US 2379 261, Publ. June 26, 1945.

[12] Kijowska D. and Kucharski M.: J. Appl. Polym. Sci., 2004, 94, 2302.

[13] Polish (European) Standards: PN-EN ISO 845.

[14] Polish (European) Standards: PN-93C/89071, ISO 884:1978.

[15] Wirpsza Z.: Poliuretany. WNT, Warsaw 1991.

\section{ВЛАСТИВОСТІ ПІНОПОЛУУРЕТАНІВ 3 ОКСАМІДНИМИ І БОРАТНИМИ ГРУПАМИ}

\begin{abstract}
Анотація. Визначено умови приготування пінополіуретанів з використанням нових бороорганічних сполук, таких як поліоли. Показано, що нові поліоли отримані двома способами: реакиією $N, N^{\prime}-б і с \quad$ (2-гідроксіетил)оксаміду (ВГЕОД) $і$ борної кислоти (БК) з надлишком етиленкарбонату (ЕК) і реакиією етерифікаиії ВГЕОД з БК з надлишком ЕК. Приведено результати визначення параметрів прочесу спінювання і дослідження властивостей піни.
\end{abstract}

Ключові слова: жорсткі пінополіуретани, оксамід, борна кислота, гідроксіалкілювання, модифікаиія структури, термостійкість, міџність на стиснення. 